[CONTRIBUtion From the Chemical Laboratory of the University of California.]

\title{
EQUILIBRIUM IN THE REACTION BETWEEN SULFUR DIOXIDE AND WATER.
}

\author{
By F. Russell Bichowsky.
}

Received November 1, 1921.

As far back as 1775 , Priestley discovered that sulfur dioxide heated with water in a sealed tube decomposes, giving sulfur and sulfuric acid according to the reaction, ${ }^{1}$

$$
2 \mathrm{H}_{2} \mathrm{O}(\mathrm{l})+3 \mathrm{SO}_{2}(\mathrm{~g})=\mathrm{S}(\lambda \mu)+2 \mathrm{H}_{2} \mathrm{SO}_{4}(\mathrm{aq}) .
$$

This reaction which is still but little known is reversible, the reverse reaction being the basis of a familiar method of preparing sulfur dioxide. Since measurements of the equilibrium constant for this reaction would, when combined with existing data, give material for the calculation of the free energy of formation of aqueous sulfuric acid, and since, taken in connection with the projected measurements of Randall of the free energy of the reactions $2 \mathrm{Hg}(1)+2 \mathrm{H}_{2} \mathrm{SO}_{4}(\mathrm{aq})=\mathrm{Hg}_{2} \mathrm{SO}_{4}(\mathrm{~s})+\mathrm{SO}_{2}(\mathrm{~g})+2 \mathrm{H}_{2} \mathrm{O}(1)$ and $\mathrm{H}_{2}(\mathrm{~g})+\mathrm{Hg}_{2} \mathrm{SO}_{4}(\mathrm{~s})=2 \mathrm{Hg}(1)+\mathrm{H}_{2} \mathrm{SO}_{4}(\mathrm{aq})$ they would give a valuable check on the value for the free energy of formation of sulfur dioxide, it was decided to investigate the equilibrium in this reaction quantitatively.

Preliminary experiments showed that in very dilute sulfuric acid the reverse reaction

$$
\mathrm{S}_{(\lambda \mu)}+2 \mathrm{H}_{2} \mathrm{SO}_{4}(\mathrm{aq})=3 \mathrm{SO}_{2}(\mathrm{~g})+2 \mathrm{H}_{2} \mathrm{O}(1),
$$

is complicated by the side reaction ${ }^{2}$

$$
4 \mathrm{~S}(\lambda \mu)+4 \mathrm{H}_{2} \mathrm{O}(1)=3 \mathrm{H}_{2} \mathrm{~S}+\mathrm{H}_{2} \mathrm{SO}_{4} .
$$

This reaction takes place quantitatively when sulfur is treated with a large excess of water in a fused silica tube. Thus $0.1603 \mathrm{~g}$. of sulfur heated with $18.0 \mathrm{~g}$. of water in a fused silica tube for 60 days to approximately $260^{\circ}$ gave $0.1220 \mathrm{~g}$. of sulfuric acid $\left(\mathrm{H}_{2} \mathrm{SO}_{4}\right)$ (calc. $0.1226 \mathrm{~g}$. ), and 0.1250 g. of hydrogen sulfide (calc. 0.1278 g.). A trace of sulfur dioxide was present. This reaction is reversible; $20 \mathrm{cc}$. of $6 \mathrm{~N}$ sulfuric acid was heated with $0.1022 \mathrm{~g}$. of hydrogen sulfide for 10 days at $250^{\circ} ; 0.112 \mathrm{~g}$. of sulfur was found (calc. $0.1282 \mathrm{~g}$.) and $0.095 \mathrm{~g}$. of sulfur dioxide showing that reaction la had to a small extent taken place simultaneously with $\mathrm{Re}$ action 2.

In order to prevent side Reaction 2 it was decided to use fairly concentrated acid and as high temperatures as practicable. Sulfur in excess was therefore heated in small silica tubes of known volumes, with a known

${ }^{1}$ Ordinary molten sulfur is, as is well known, a mixture of $S_{\lambda}$ (soluble sulfur) and $S_{\mu}$ (insoluble sulfur), and perhaps other species. $B y S\left(\lambda_{\mu}\right)$ is meant the equilibrium mixture of $S_{\lambda}$ and $S_{\mu}$. Cf. Kruyt, $Z$. physik. Chem., 64, 513 (1908).

${ }^{2}$ For preliminary investigations on this reaction and other reactions of sulfur, see Lewis, Randall and Bichowsky, Thrs Journal, 40, 356 (1918). 
amount $(1 / 3$ the volume of the tube) of sulfuric acid of the strength desired. At the temperature used $\left(312^{\circ}\right)$ even Pyrex glass is rapidly attacked by'sulfuric acid, wherefore the use of silica tubes. At this temperature, moreover, the total pressure in the tube is in the neighborhood of 150 atmospheres. The tube had therefore to be protected from bursting by being enclosed in a steel bomb partially filled with water, in order to counterbalance the pressure inside and outside the small silica tubes. At the end of 12 days (other experiments showed that equilibrium was not reached in 3 days but was in 7) the bomb was cooled and opened and the sulfur dioxide content of the silica tubes determined by breaking them under standard iodine solution and titrating back with thiosulfate. The results are given in Table I; Col. 1 gives the weight concentration of the acid used (mols. per $1000 \mathrm{~g}$. of solution), Col. 2 the amount of acid (solution) in g. introduced into the tube, Col. 3 the volume of the tube in $\mathrm{cc}$, Col. 4 the amount of iodine used, in mols. It is possible, assuming that the only reaction taking place in the tube was $1 \mathrm{a}$, by a laborious calculation, the details of which will not be given, to determine the total pressure of sulfur dioxide (Col. 5) present at equilibrium, and also the concentration of sulfuric acid and water at equilibrium. From these data, using the methods of the latter part of this paper, the equilibrium constants for the reaction $2 \mathrm{H}_{2} \mathrm{SO}_{4}(N=0.101)+\mathrm{S}_{(\lambda \mu)}=3 \mathrm{SO}_{2}(\mathrm{~g})+2 \mathrm{H}_{2} \mathrm{O}$ were calculated and are given in Col. 6 .

\begin{tabular}{|c|c|c|c|c|c|}
\hline \multirow[b]{2}{*}{$\begin{array}{c}\mathrm{H}_{2} \mathrm{SO}_{4} \\
M\end{array}$} & \multicolumn{4}{|c|}{ TABLE I } & \multirow[b]{2}{*}{$K_{p} \times 10^{-1}$} \\
\hline & $\begin{array}{l}\text { Wt. } \\
\text { G. }\end{array}$ & $\begin{array}{l}\text { Vol. } \\
\text { Cc. }\end{array}$ & $\begin{array}{l}\mathrm{I}_{2} \\
M\end{array}$ & $\begin{array}{c}P_{\mathrm{SO}_{2}} \\
\text { (Atm.) }\end{array}$ & \\
\hline \multirow{4}{*}{2.120} & 1.006 & 3.018 & 0.00198 & 48.6 & 5.5 \\
\hline & 1.040 & 3.443 & 0.00205 & 41.1 & 2.3 \\
\hline & 0.873 & 2.944 & 0.00172 & 40.7 & 2.1 \\
\hline & 0.952 & 3.229 & 0.00191 & 40.6 & 1.7 \\
\hline \multirow{7}{*}{0.947.} & 0.836 & 3.339 & 0.000653 & 13.0 & 4.9 \\
\hline & 0.806 & 3.643 & 0.000660 & 11.4 & 3.9 \\
\hline & 0.874 & 3.504 & 0.000631 & 12.0 & 2.9 \\
\hline & 1.238 & 3.383 & 0.000264 & 7.2 & 11.2 \\
\hline & 0.995 & 3.139 & 0.000248 & 6.3 & 14.5 \\
\hline & 1.179 & 4.383 & 0.000392 & 6.4 & 28.0 \\
\hline & 0.925 & 3.277 & 0.000244 & 5.5 & 9.9 \\
\hline
\end{tabular}

This constant varies greatly and does not agree with that found by our later method using more concentrated acid. Therefore it may be concluded that for acids of this strength Reaction 2 cannot be neglected, although experiments showed it possible, under proper conditions, to cool our tubes rapidly enough so that both hydrogen sulfide and sulfur dioxide could be detected. It was felt that the danger of the reaction $2 \mathrm{H}_{2} \mathrm{~S}+\mathrm{SO}_{2}$ $=2 \mathrm{H}_{2} \mathrm{O}+3 \mathrm{~S}$ taking place at appreciable amount during cooling was too great to warrant further experiments with acids of these concentrations. 
Experiments of this type, using acids of a mol fraction greater than 0.1 and temperatures above $275^{\circ}$, are impractical because of the high pressure of sulfur dioxide at equilibrium; besides any "quenching" method, where the composition of the equilibrium mixture is inferred from the analysis of a rapidly cooled sample, is always open to the suspicion (a) that equi-

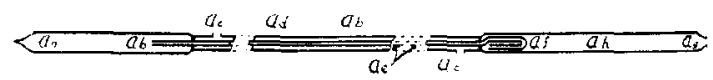

Fig. 1.-Fused silica reaction tube

librium was not really established, and (b) that some interfering reaction took place during cooling. It was therefore thought wise to use some method in which the equilibrium pressure could be measured directly and in which surety could be had that equilibrium had been really reached.

The final apparatus consisted essentially of a quartz reaction tube $A$ (Figs. 1 and 2) inverted in a mercury-filled steel bomb B.

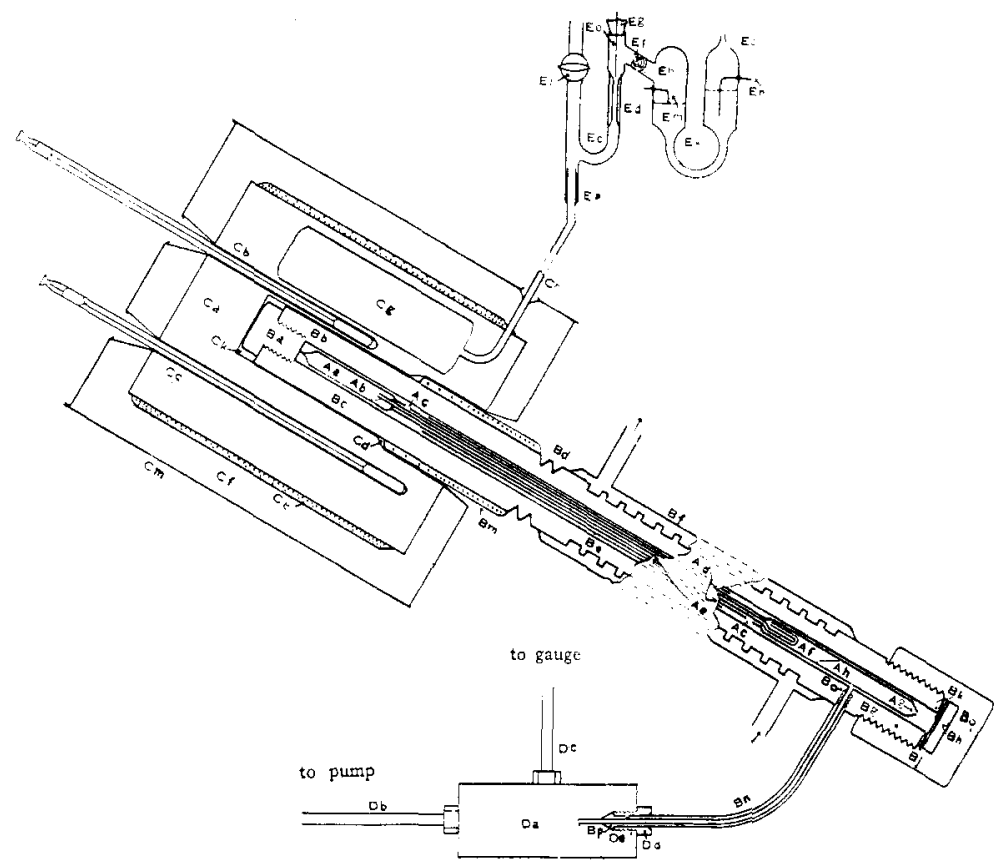

Fig, 2,-Ensemble of apparatus.

, Only the upper end of bomb and tube was heated, the lower end, where the acid was in contact with the mercury, being kept cool by the water jacket Bf. The upper or hot section $\mathrm{Aa}$ of the tube was filled with sulfuric acid of the strength desired, and contained a little sulfur trapped in the pocket $\mathrm{Ab}$. This section communicated by means of the long quartz capillary Ae with the lower section Ah. In order to prevent breaking, this capillary was reinforced by having a heavy quartz tube Ad fused to it. This tube also served to decrease the cross section of mercury in that part of the bomb where 
there was a temperature gradient. To prevent the bursting of the capillary and its protecting tube, the space between them communicated with the mercury without through the openings $\mathrm{Ac}^{\prime}$ and $\mathrm{Ac}^{\prime \prime}$. The lower and cold end of the reaction tube was enlarged into a quartz chamber $\mathrm{Ah}$, which at the beginning of each experiment was filled with mercury. This mercury and the sulfuric acid in the capillary were in contact through the capillary trap Af, which served the triple purpose of communicating the pressure generated in one part to the other, of preventing mercury from running into Aa in the course of filling, and of trapping any small bubbles of gas that might form in $\mathrm{Ah}$. As the temperature was raised at the upper end of the tube the point of contact between the sulfuric acid and the mercury moved down the tube to, say, $A^{\prime}$, due to the fact that the coefficient of expansion of sulfuric acid is much larger than that of mercury. For this reason and because it was desirable to be able to vary the gas space in Aa the tube Ah was made approximately twice as large as $\mathrm{Aa}$ (the volume of $\mathrm{Aa}$ in our apparatus was about $4 \mathrm{cc}$ ). The mercury in $A \mathrm{~h}$ communicated through the capillary opening $\mathrm{Ag}$ with the mercury in the outer bomb. Thus any pressure generated in $\mathrm{Aa}$ was communicated through Ae, Af, Ah and Ag to the mercury in the outer bomb in which the tube was floating. Thus there was no danger of crushing or exploding the quartz tube $^{3}$ Pressure generated by, or applied to, the reaction mixture is measured through $\mathrm{Bn}$ by the gage at De (in our case, Shaffer and Budenberg Test Gage 493459 reading from zero to 200 atmospheres). The pressure inside of the apparatus and thus the volume of the gas space in $\mathrm{Aa}$ could be varied by means of a plunger pump at $\mathrm{Db}$.

Our apparatus is thus in effect a quartz-lined bomb, but the principle of counterbalancing the pressure inside and outside of a floating hot-cold tube of some material not attacked by the reaction mixture is of much wider application than this particular reaction. A similar apparatus would be almost ideal for measuring vapor pressures of both pure substances and solutions at high pressures and particularly for studying the critical phenomena. It is essential for any work at high pressure that the steel portions of the apparatus be very carefully designed and constructed. For this portion of the work we are very greatly indebted to the very able assistance of Mr. G. F. Nelson, the mechanic of this laboratory.

The steel bomb $B$ was made of thick-walled hydraulic tubing of inside diameter of $12 \mathrm{~mm}$, outside diameter of $37 \mathrm{~mm}$, and length of $84 \mathrm{~cm}$. The dimensions of the quartz tube were such that it almost completely filled the bomb, thus preventing heat leak. The upper or hot end of the bomb was plugged by a simple serew plug $\mathbf{B a}$, set down hard on a collar $\mathrm{Bb}$. This method was adopted only after trying in vain to fuse the end together autogeneously with an oxy-acetylene flame. Though to the eye the metal seemed homogeneous, such joints were always too porous for our purposes. The lower or cold end of the bomb, where the joint has to be opened at each filling of the apparatus, was sealed by a joint designed by Mr. Nelson. The essential feature of this joint is the soft iron disc $\mathrm{Bj}$ placed in a recess in the hardened floating plug $\mathrm{Bh}$. In sealing this joint, the bearing between $\mathrm{Bh}$ and $\mathrm{Bq}$ is lubricated with graphite so that when the cap, Bq, is screwed into place the soft iron disc $B j$ is pressed, not screwed down on the shoulder Bk. As there is now no tendency for $\mathrm{Bj}$ to be stripped by slipping past slight roughnesses on $\mathrm{Bk}$, the bomb holds moderate pressures, say up to 300 atmospheres, very satisfactorily, and the joint can be repeatedly made and unmade. Copper could not be used for the disc $B \mathrm{j}$, as under pressure it amalgamates too rapidly with mercury. The bomb was provided with a cooling jacket $\mathrm{Bf}$, the portion of the bomb

3 There is no reaction between mercury and sulfuric acid at low temperatures. 
covered by the cooling jacket being deeply threaded to provide extra cooling surface. Just below the part of the bomb which was in the furnace were cut two deep V-shaped grooves Bd. These, by reducing the thickness of the metal in this, the sharpest part, of the temperature gradient, greatly reduced the heat leak without much decreasing the strength of the tube. The small tube $\mathrm{Bn}$ was simply screwed down in shellac on a seat Bo. This joint was permanent and so does not require the more elaborate devices which were necessary for the constantly re-opened joint $\mathrm{Dd}$. In this joint the cone Bp which is brazed on the end of the tube $\mathrm{Bn}$, is made with a taper about 5 degrees less than the seat $\mathrm{De}$, so that when forced home by screwing up the vanadium-steel nipple $\mathrm{Dd}$ the tip of $\mathrm{Bp}$ is sprung against the seat in such a way that any liquid pressure in the tube tends to seat Bp still more tightly. Such joints, when properly constructed, can be made and remade time after time without the slightest leak. The unions at $\mathrm{Db}$ and Dc are similar. The pump used in the apparatus was simply an old screw-plunger pump with a special sliding (rather than turning) steel and leather plunger packing. This pump was seated on an aluminum washer protected by shellac. To make unnecessary the very special precautions that are needed to hold a sliding contact against mercury a thin layer of heavy oil was placed on top of the mercury. With this precaution this simple pump showed no leak at 200 atmospheres. The tube De was also filled with oil to protect any brass in the gage from the mercury.

With such an apparatus as this with which the heat leak is so very large, the problem of designing a thermostat, keeping the upper end of the bomb at $300^{\circ}$ while the lower end is kept cold, is no light one. The thermostat must have large heating capacity, the minimum of temperature lag, and the greatest possible heat conductivity, the heat leak being mostly at one point where the bomb enters the thermostat.

To meet these requirements the thermostat was made of a heavy casting of aluminum $\mathrm{Ca}$ in which had been cast the steel bulb $\mathrm{Cg}$ and stem $\mathrm{Ch}$ of the temperature regulator. The heating was done with two coils of Nichrome wire wound on a thin coating of an insulating cement and protected with the same material. In order to counterbalance in some degree the temperature gradient down the bomb an auxiliary heating coil $\mathrm{Bm}$ was wound in cement on the upper portion of the bomb itself. This auxiliary coil fitted tightly in the space $\mathrm{Cd}$ of the furnace. The temperature of the furnace was read by two thermometers $\mathrm{Cc}$ and $\mathrm{Cb}$ which fitted closely into two holes bored for that purpose into the aluminum casting. The whole furnace was insulated by $25 \mathrm{~mm}$. of asbestos-magnesia mixture $\mathrm{Cf}$ placed between the tin jacket $\mathrm{Cm}$ and the casting. As such a thermostat consumed a total of about 3 kilowatts at the higher temperatures, almost $1 / 3$ of which must pass through the regulating coil, the design of the make-and-break for the relay is a matter of some interest. The wipe contact, long-armed relay set shortly to be described by Randall, meets this demand nicely. However, to make this instrument work, enough current must be sent through the mercury make-and-break to cause it to arc badly. Moreover, mercury in an iron regulator at this temperature seems to become foul rapidly even with no sparking. To avoid these difficulties it was decided to keep an atmosphere of hydrogen over the mercury. For this reason the small automatic electrolytic hydrogen generator, shown at Ek, connected in parallel with the spark, was made continuous with the other glass parts of the regulator. It is advisable, though not necessary, to have a small plug of glass wool at Ef to prevent spray and to have the connections of the 2 arms of the U-tube somewhat constricted to prevent sudden gurgitation. With this apparatus the usual platinum wire at Ee can be replaced by Nichrome. A rubber stopper at Eg makes a satisfactory seal. Fine regulation can be made by sliding the wire in the stopper, and 
coarse by withdrawing or adding mercury through $\mathrm{Eb}$. Phosphoric acid will be found the best electrolyte for this miniature hydrogen generator as for most others. It does not: stick to the walls and form short circuits as potassium hydroxide is apt to do, nor does it give off sulfur dioxide at the electrode as sulfuric acid may do, nor does its vapor react with mercury as hydrochloric acid does. With such an apparatus, a mercury contact will keep clean indefinitely even with heavy sparking.

It is of course important that an apparatus of this sort be filled very carefully and that no air or moisture be trapped in it. For these reasons it was found desirable to fill the apparatus in a vacuum. To do this the reaction tube $A$ was removed from the bomb and connected through a 2-way stopcock to the vacuum line and to an evacuated vessel containing boiled-out sulfuric acid of the strength desired. After thoroughly evacuating the quartz apparatus, a process which could be accelerated by heating, enough sulfuric acid was introduced to fill the apparatus completely, and the tube then removed from the pump. The apparatus was then inverted and mercury poured in to fill Ah. The mercury could not run into the other parts of the tube because of the trap Af. The quartz tube was then carefully dried on the outside and placed in the bomb, which was then tightly sealed, evacuated, and filled with mercury. The joint Dd was then quickly made but not completely screwed up, and the bomb placed in the proper inclined position. The joints were then all tightened and pressure applied from $\mathrm{E}$ to test for leaks. The furnace was then put in place and rapid heating begun, the lower end of the apparatus, of course,

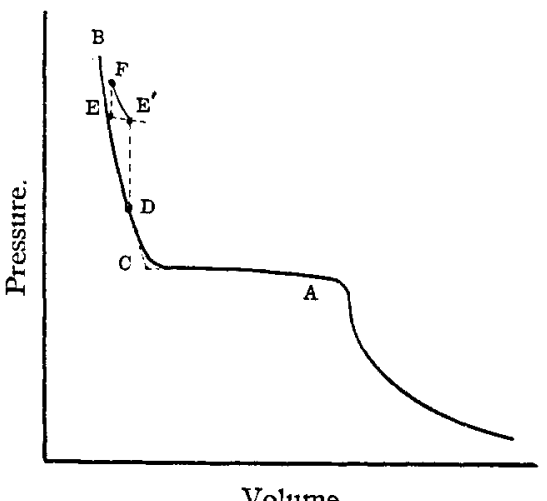

Volume.

Fig. 3.--Pressure-volume isotherm. being cooled with running water. After the apparatus had reached the required temperature, pressure-volume isotherms were made; that is to say, the volume of the apparatus was changed by means of the calibrated pump and the pressure read corresponding to the various volumes. If heating had been done so rapidly that but little sulfur dioxide had time to form, the isotherm obtained was the regular $P-V$ isotherm for sulfuric acid (Fig. 3), the portion of the curve from $\mathrm{C}$ to $\mathrm{A}$ representing the vapor pressure of the acid at various volumes of the system, the portion from $B$ to $C$ representing, when corrected for, a compressibility of the mercury and cold sulfuric acid and for the dilation of the instrument, the change of pressure of the hot liquid sulfuric acid for a given change of volume. The slight slope of the portion of the curve $\mathrm{C}$ to $\mathrm{A}, i . e$. , the slight variation of the vapor pressure with the total volume of the system is due to the evaporation of the water into the varying gas space above the sulfuric 
acid, changing the concentration of the acid. Ideally $\mathrm{BC}$ and $\mathrm{AC}$ should join at a sharp angle if no sulfur dioxide had time to form or if no gas was trapped in the system due to faulty filling. In this case the pressure corresponding to the point $\mathrm{C}$ would be the vapor pressure of the sulfuric acid in contact with zero gas space, and hence of the concentration initially introduced. Practically there was always a slight curvature at $\mathrm{C}$, but its position could be approximated by extrapolating the straight parts of $\mathrm{BC}$ and $\mathrm{AC}$ until they crossed.

Having thus obtained the preliminary isotherm, the pressure was set a little above the probable wapor pressure (Point D, Fig. 3) of the acid and the reaction allowed to proceed. Equilibrium was usually reached in a couple of days (for temperatures about $300^{\circ}$ ), pressure going up to say $\mathrm{E}$. The volume of the apparatus was then changed the pressure increasing to say $F$ (Fig. 3). Now without changing the volume the heating was continued and we would find, the pressure $\mathrm{F}$ being above equilibrium, that the pressure would fall to $\mathrm{E}^{\prime}$. Thus equilibrium could be approached from both sides; moreover, since the point $\mathrm{E}^{\prime}$ could be so chosen as to lie as nearly as desired to the curve $\mathrm{CB}$, equilibrium could be obtained with but zero gas space. Thus no appreciable change of concentration of the acid was possible. Moreover, it will be noted that in the cases where the mol. fraction of sulfur dioxide is $3 / 2$ that of water, the composition of the acid (as is approximately the case in Expts. 6, 7 and 8) is independent of the gas space, no matter how large that may be.

By means of this procedure it was possible to obtain measurements approaching equilibrium from both sides, which would check, except at the highest pressures, to within one atmosphere.

Table II gives the results of some preliminary experiments in which the vapor pressure of sulfuric acid of several strengths was determined either in the absence of sulfur, or in the presence of sulfur before the sulfur dioxide had time to be formed. In this table the first column gives the number of the experiment, the second the mol fraction $\mathrm{N}_{\mathrm{H}_{2} \mathrm{SO}_{4}}$ of sulfuric acid, the third the absolute temperature, and the fourth the pressure, $p^{\prime}{ }_{2\left(\mathrm{H}_{2} \mathrm{O}\right)}$ in atmospheres. ${ }^{4}$ The measurements with pure water were made to test the method and the results agree closely with those obtained by other observers. As the temperature approaches the critical temperature of water the difficulty of determining the vapor pressure becomes greater owing to the difficulty of finding a flat portion of the pressure-volume isotherm, but if care be taken to eliminate all foreign gas these difficulties are reduced to a minimum. In Expt. 1 sulfur was present and only one point was determined before sulfur dioxide began to form; Expts. 2, 3 and 4 were made in the absence of sulfur; Expts. 5 and 6 with sulfur present, according to the method outlined.

- The gas phase is essentially pure water vapor. 
TABLE II

VAPOR Pressures OF SUlfuric Acid

$\begin{array}{cccc}\text { Expt. } & N_{\mathrm{H}_{2} \mathrm{SO}} & T & p_{2} \\ 1 \mathrm{~S} & 0.160 & 540 & 30 \\ 2 & 0.101 & 588 & 84 \\ 3 & 0.101 & 543 & 45 \\ 7 & 0.101 & 496 & 19.5 \\ 5 & 0.101 & 593 & 95 \\ 6 & 0.101 & 563 & 58 \\ 7 & 0.0 & 498 & 25.5 \\ 8 & 0.0 & 563 & 72 \\ 9 & 0.0 & 612 & 141\end{array}$

The results for the equilibrium measurements are given in 'Table III. The first column gives the absolute temperature $T$; the second the mol. fraction of the sulfuric acid; the third the total pressure $P_{E}$ of water vapor, sulfur vapor and sulfur dioxide; the fourth the pressure of water vapor from sulfuric acid of the strength given, in the absence of sulfur dioxide. ${ }^{5}$

TABLE III

\begin{tabular}{|c|c|c|c|c|c|c|c|c|}
\hline & & & EQUILI & BRIUM I & MEASUREM & IENTS & & \\
\hline & Col. 1 & 2 & 3 & 4 & $\bar{i}$ & 6 & 7 & 8 \\
\hline & $T_{\text {abs. }}$ & $N_{\mathrm{H}_{2} \mathrm{SO}_{4}}$ & $I^{\prime} E$ & ${ }^{P} \mathrm{H}_{2} \mathrm{O}$ & $\log f_{\mathrm{H}_{2} \mathrm{O}}$ & $\log \alpha_{\mathrm{H}_{2} \mathrm{SO}}$ & $\frac{\log \alpha_{\mathrm{H}_{2} \mathrm{SO}_{4}}}{P_{2}}$ & $\log f_{\mathrm{H}_{2} \mathrm{O}}^{2}$ \\
\hline 1 & 613 & 0.041 & 185 & 138 & 2.05 & -3.04 & -3.25 & 2.06 \\
\hline 2 & 58.5 & 0.041 & 114 & 96 & 1.89 & -2.98 & -3.06 & 1.90 \\
\hline 3 & .561 & $0.10 \mathrm{l}$ & 90 & 59 & 1.71 & -1.34 & -1.42 & 1.71 \\
\hline 4 & 598 & 0.101 & 197 & 98 & 1.92 & $-1.5 j 5$ & -1.79 & 1.94 \\
\hline 5 & 588 & 0.101 & 166 & 85 & 1.86 & -1.50 & -1.69 & 1.88 \\
\hline 6 & 537 & 0.160 & 84 & 28 & $1 . \pm 1$ & -0.54 & -0.63 & 1.42 \\
\hline 7 & 572.5 & 0.160 & 185 & 49 & 1.65 .5 & -0.85 & -1.07 & 1.68 \\
\hline 8 & 562 & 0.160 & 150 & 42 & 1.58 & -0.76 & -0.92 & 1.60 \\
\hline 9 & 527 & 0.363 & 190 & $\ldots$ & $\ldots$ & $\ldots \bullet$ & $\ldots \ldots$ & $\ldots$ \\
\hline & Col. 9 & 10 & ${ }_{P_{E}}^{11}$ & $\underset{0}{12}$ & $\begin{array}{l}13 \\
P_{F}\end{array}$ & 14 & 15 & \\
\hline & $\log f_{\mathrm{H}_{2} \mathrm{O}}$ & $N_{\mathrm{SO}_{2}}$ & $\begin{array}{l}1 E_{2} \\
\mathrm{VSO}_{2}\end{array}$ & $\log f_{\mathrm{SO}_{2}}$ & $\log f_{\mathrm{SO}_{2}}^{E}$ & $\log K_{P}$ & I & \\
\hline 1 & 2.13 & $(0,13)$ & $(196)$ & 2.14 & $(1,26)$ & $(13.6)$ & $(125.5)$ & \\
\hline 2 & 1.94 & $(0.10)$ & $(336)$ & 2.03 & $(1.02)$ & $(12.2)$ & $(126.8)$ & \\
\hline 3 & 1.84 & 0.25 & \pm 10 & 1.87 & 1.27 & 10.11 & $124 . \tilde{3}$ & \\
\hline+ & 2.08 & 0.27 & 172 & 2.15 & 1.58 & 12.21 & 124.0 & \\
\hline 5 & 2.03 & 0.29 & 202 & 2.09 & 1.55 & 11.68 & 124.3 & \\
\hline 6 & 1.78 & 0.57 & 414 & 1.84 & 1.59 & 8.87 & 126.7 & \\
\hline$\vec{i}$ & 1.97 & 0.49 & 166 & 2.11 & 1.80 & 10.89 & 124.4 & \\
\hline 8 & 1.93 & 0.52 & 205 & 2.04 & 1.76 & 10.32 & 125.1 & \\
\hline 9 & $\ldots$ & $\ldots$ & $\ldots$ & $\ldots$ & $\ldots$ & Mean & $\ldots \ldots$ & \\
\hline
\end{tabular}

${ }_{5}^{5}$ The experimental part of this paper was completed in June 1916, while working under the direction of $G$. N. Lewis, to whom the author wishes to express his gratitude. Preliminary calculations of the equilibrium constant were made by Dr. Lewis and the author at that time. The present calculations are a complete revision of these earlier ones. 
Before proceeding to an explanation of the remaining columns in Table III, we must point out the extraordinary difficulties attending the calculation of the equilibrium constant. If measurements could have been carried on at low pressures and temperatures, and if sulfuric acid were a perfect solution the equilibrium constant for the reaction $\mathrm{S}+2 \mathrm{H}_{2} \mathrm{SO}_{4}=$ $2 \mathrm{H}_{2} \mathrm{O}+3 \mathrm{SO}_{2}$ would be of course simply

$$
K_{p}=\frac{\left[\mathrm{H}_{2} \mathrm{O}\right]^{2}\left[\mathrm{SO}_{2}\right]^{3}}{\left(\mathrm{H}_{2} \mathrm{SO}_{4}\right)^{2}}
$$

where the quantities in brackets are pressures and $\left(\mathrm{H}_{2} \mathrm{SO}_{4}\right)$ is the mol fraction of $\mathrm{H}_{2} \mathrm{SO}_{4}$, $\left[\mathrm{H}_{2} \mathrm{O}\right]$ the vapor pressure of water over sulfuric acid of the strength used (i.e., the measured vapor pressure of sulfuric acid), and $\left[\mathrm{SO}_{2}\right]$ the difference between the vapor pressure of the sulfuric acid and the total measured equilibrium pressure. However, in our actual case the gases and solution are so imperfect that more elaborate methods are necessary.

The Calculation of the Fugacity of Water.-The equation for the equilibrium constant written above is, however, still exact if instead of using the pressures and concentrations of the substances involved we use their fugacities and activities. Now the pressure $P$ of any gas is related to the fugacity $f$ at any temperature and pressure by the equation

$$
\mathrm{R} T \ln \frac{P}{f}=\int_{0}^{P}\left(\mathrm{v}^{\prime}-\mathrm{v}\right) d p,
$$

where $\mathrm{v}^{\prime}$ is the molal volume of a perfect gas, $\mathrm{v}$ that of the actual gas, and the integral from zero pressure to the pressure in question gives the area between the isotherm of a perfect gas and that of the actual gas ${ }^{6}$ for the temperature and presure used.

For water vapor the compressibility has been accurately determined at various temperatures and pressures, and the results are represented with fair accuracy by the equation of state given by Linde, ${ }^{7}$ which for one mol becomes in terms of atmospheres, liters and absolute temperatures,

$$
P \mathrm{v}=0.0823 T-p(1+0.0206 P)\left(\frac{29050000}{T^{3}}-0.0948\right) .
$$

Combining (1) and (2), and integrating, we find

$$
\mathrm{R} T \ln \frac{P}{f}=p(1+0.0103)\left(\frac{29050000}{T^{3}}-0.948\right) \text {. }
$$

This equation allows ts to calculate from the measured pressure of water over the sulfuric acid, at any temperature, the fugacity of the water at that temperature and pressure.

${ }^{6}$ Lewis, Proc. Am. Acad., 37, 49 (1901); Z. physik. Chem., 38, 205 (1901).

' Linde, !Ver. deut. Ing. Forschungsarb., Berlin, 21, 33 (1905); Z. Ver. deut. Ing., 49, $1745(1905)$. 
Now the close agreement between the measurements on the vapor pressure of the acid made in the presence of sulfur and sulfur dioxide (Table II) and those made in the absence of sulfur and sulfur dioxide justifies us in assuming that sulfur and sulfur dioxide are not sufficiently soluble in our acid at the temperatures and pressures used to affect the activity of the water in the solution. Therefore we may assume that the values for the fugacity of water calculated from the vapor pressure of the water over the sulfuric acid will be the same (excepting for a small correction due to the compression of the aqueous acid by the excess pressure of sulfur dioxide) whether sulfur dioxide is present or absent. Hence in order to calculate the fugacity of water in our mixture all that is needed is the vapor pressure of the acid at our concentration and temperatures. For these vapor pressures we have, in the first place, our measurements (Table II) and, secondly, at lower temperatures, i.e., $184.5^{\circ}$ and $218^{\circ}$, unpublished values ${ }^{8}$ of the vapor pressure of sulfuric acid of various strengths, due to Randall and James, and at still lower temperatures the measurements of Burt, ${ }^{9}$ Briggs, ${ }^{10}$ Tammann, ${ }^{11}$ Sorel, ${ }^{12}$ Regnault, ${ }^{18}$ Brönsted, ${ }^{14}$ and Dieterici. ${ }^{15}$ Using these values, a plot was made giving the best values of the logarithm of the vapor pressure against the reciprocal of the absolute temperature for various concentrations of acid. The values $P_{\mathrm{H}_{2} \mathrm{O}}$ for our concentrations and temperatures read off this plot are given in Col. 4 of Table III. Log $f_{\mathrm{H}_{2} \mathrm{O}}$, calculated from Equation 3 is given in Col. $5 .{ }^{16}$

There is, however, another method of obtaining the fugacity of the water over the sulfuric acid at our temperatures. The fugacity change is connected by means of the equation

$$
\Delta \mathrm{F}=\mathrm{R} T \ln \frac{B}{f_{A}} .
$$

with the free energy change of a process which consists of taking a mol. of

${ }^{8}$ These values are: $T=184.4^{\circ} ; N=0.1509, p=5.72, N=0.2101, p=3.84, N=0.2795$, $p=2.25$ for $T=218.0^{\circ} ; N=0.1509, p=12.01, N=0.2101, p=7.85, N=0.2795, p=4.87$, $N=0.300, p=4.20$ (pressures in atmos., concentrations in mol. fractions). Quoted by permission.

${ }^{9}$ Burt, J. Chem. Soc., 85, 1339 (1904).

${ }^{10}$ Briggs, J. Soc. Chem. Ind., 22, 1375 (1903).

11 Tammann, Mérn. Acad. Pétersbourg [7] 35, (1885), quoted from LandoltBörnstein-Roth "Tabellen," 1912, p. 427.

${ }^{12}$ Sorel, $Z$. angew. Chem., 2, 272 (1889).

${ }^{13}$ Regnault, Ann. chim. phys., [3] 15, 179 (1845).

14 Brönsted, $Z$. physik. Chem., 68, 708 (1909-10).

${ }_{15}$ Dieterici, Wied. Ann., 42, 513 (1891); 50, 47 (1893); 62, 616 (1897).

${ }^{16}$ Due to an accident in the last of the experiments with sulfuric acid of mol. fraction 0.363 the vapor pressure of water was not obtained and there seems to be no way of estimating this pressure with any degree of certainty. No measurements were made on the vapor pressure of the most dilute acid, but here interpolation from the results at higher concentration can be used with some confidence. 
any substance from the state $\mathrm{A}$ to the state $\mathrm{B}$. Our process is the reaction $\mathrm{H}_{2} \mathrm{O}(\mathrm{g})=\mathrm{H}_{2} \mathrm{O}$ (in $\mathrm{H}_{2} \mathrm{SO}_{4}$ ), which is more conveniently treated as the sum of the processes $(a) \mathrm{H}_{2} \mathrm{O}(\mathrm{g})=\mathrm{H}_{2} \mathrm{O}(1)$, and (b) $\mathrm{H}_{2} \mathrm{O}(1)=\mathrm{H}_{2} \mathrm{O}$ (in $\mathrm{H}_{2} \mathrm{SO}_{4}$ ). The free energy change in Reaction $a$ may be calculated from data given by Lewis and Randall from the equation

$$
\Delta \mathrm{F}=-13259-9.21 T \ln T-0.00097 T^{2}+0.00000037 T^{3}+90.20 T T^{17}
$$

The free energy change in Process $b, i . e$. , the partial free energy of solution of water in various strengths of sulfuric acid, may be calculated at $2.5^{\circ}$ from the vapor pressure of the acid at that concentration and temperature, where, assuming that water vapor at these low pressures (less than $2.5 \mathrm{~mm}$.) is a perfect gas, we may substitute pressures in place of fugacities, in Equation 4 , and obtain the equation

$$
\Delta \mathrm{F}=\mathrm{R} T \ln \frac{P_{\mathrm{H}_{2} \mathrm{O}}}{P_{\mathrm{H}_{2} \mathrm{O}}^{\circ}},
$$

$P_{\mathrm{H}_{2} \mathrm{O}}$ being the measured vapor pressure of water over sulfuric acid, and $P_{\mathrm{H}_{2} \mathrm{O}}^{\circ}$ the vapor pressure of pure water, i. e., $23.8 \mathrm{~mm}$. The best values for the vapor pressure of water over sulfuric acid at $25^{\circ}$ are those of Brönsted ${ }^{14}$ and of Regnault. ${ }^{13}$ These agree well enough except at our highest concentration, where unfortunately neither value is consistent with the value obtained by indirect methods from freezing-point determinations, and where apparently there is no way of estimating $\Delta \overline{\mathrm{F}}_{298}$. The values for $\Delta \overline{\mathrm{F}}$ for Process $b$ for our other concentrations are given in Col. 2, Table IV. Col. 1 of this table gives the corresponding concentration of the acid

\begin{tabular}{|c|c|c|c|c|c|}
\hline & & $\begin{array}{r}T_{A} \\
F_{R E E} E_{N}\end{array}$ & $\begin{array}{l}\text { IV } \\
\text { CHANGE }\end{array}$ & & \\
\hline $0^{x}$ & $\overline{\Delta F}_{2980}$ & $\overline{S H}_{290} 0$ & $\int_{0}^{5 \bar{T}}$ & $\overline{\mathrm{SH}}_{0}$ & $0^{I}$ \\
\hline 0.0411 & -71 & -27 & -0.32 & +66 & -2.28 \\
\hline 0.101 & -296 & -282 & +0.68 & -479 & +4.49 \\
\hline 0.160 & -615 & -686 & -0.68 & -489 & -4.30 \\
\hline 0.363 & & -2570 & -6.37 & $\ldots \ldots$ & \\
\hline
\end{tabular}
expressed in mol fractions of sulfuric acid.

In order to obtain $\Delta \overline{\mathrm{F}}_{\mathrm{H}_{3} \mathrm{O}}$ at other temperatures we must know $\Delta \overline{\mathrm{H}}_{\mathrm{H}_{2} \mathrm{O}}$, the partial molal heat of solution of water in sulfuric acid of our concentrations, and the change of that quantity with the temperature. Rümelin ${ }^{18}$ has measured $\lrcorner \overline{\mathrm{H}}_{\mathrm{H}: \mathrm{O}}$ directly at $17^{\circ}$, and the same quantity may be calculated from data on the integral heat of solution of water given by Brönsted. ${ }^{19}$ The values of $\Delta \overline{\mathrm{H}}_{290}$ obtained by drawing the best smooth curve through these values are given in Table IV, Col. 3. The values for $\overline{\mathrm{c}}_{\mathrm{pH}_{2} \mathrm{O}}$ (the partial molal heat capacity of water in solutions of sulfuric acid)

${ }^{17}$ Lewis and Randall, THIS JOURA-AL, 36, 1980 (1914). We have arbitrarily taken the heat capacity of water as 18.01 at all temperatures. This value cancels out.

${ }^{18}$ Rümelin, Z. physik. Chem., 58, 449 (1907).

${ }^{19}$ Brönsted, Ref. 14, Table 12. Recalculation is necessary. 
are calculated, using the method of intercepts, ${ }^{20}$ from the measurements of Biron ${ }^{21}$ on the specific heat of sulfuric acid : water mixtures. The values obtained for $\Delta \bar{\Gamma}_{\mathrm{H}_{2} \mathrm{O}}$, again assuming that $\mathrm{C}_{p}$ for pure water is 18.01 are given in Col. 4, Table IV. Values of $\Delta \overline{\mathrm{H}}_{0}$ and I obtained by the usual methods, assuming $\Delta \bar{\Gamma}_{\mathrm{H}_{2} \mathrm{O}}$ constant, are given in Cols. 5 and 6 , respectively, of this table. The values of $\Delta \overline{\mathrm{H}}_{0}, \Delta \bar{\Gamma}_{\mathrm{H}_{2} \mathrm{O}}$ and $\mathrm{I}$ for the reaction $\mathrm{H}_{2} \mathrm{O}(\mathrm{g})=$ $\mathrm{H}_{2} \mathrm{O}$ (in $\mathrm{H}_{2} \mathrm{SO}_{4}$ ) are simply the sum of the $\Delta \overrightarrow{\mathrm{H}}_{0}$ 's, I's, etc., for Equations $a$ and $b$. We may therefore calculate the fugacity of the water for the various concentrations and temperatures used in these experiments. The values calculated are consistent both with the data of Randall and James and our own data, and within the limit of error, i. e., 1\% of those directly estimated in Table III.

These fugacities are, however, still subject to a slight correction due to the fact that the dissolved water is not under its own vapor pressure, but under the total pressure $P_{E}$. The effect of pressure on fugacity is given by the equation

$$
\left(\frac{\partial \ln f}{\partial P}\right)_{T}=\frac{\overline{\mathrm{v}}}{\mathrm{R} T},
$$

where $\vec{v}$, the partial molal volume of water dissolved in sulfuric acid, may be calculated at $25^{\circ}$, using the method of intercepts, from the very accurate data on the density of sulfuric acid solutions given by Domke and Bein. ${ }^{21}$

For the temperatures of these experiments $\overline{\mathrm{v}}$ may be approximated by assuming that at all temperatures the ratio of $\bar{v}$ to the density of pure water is constant. The values of fugacity of water so corrected are given in Col. 8, Table III.

Activity of Sulfuric Acid.-The standard state for sulfuric acid will be taken as hypothetical molal, $i . e$., the state in which $a_{2} / N_{2}=1 .^{22}$ Lewis and Randal1 ${ }^{23}$ have given a table of the activity coefficients for sulfuric acid extending to a concentration of $20 \mathrm{molal}(N=0.26)$. Unfortunately no way seems available for extending this table to $N=0.363$. The values for $\Delta \mathrm{F}$, for the reaction $\mathrm{H}_{2} \mathrm{SO}_{4}(M)=\mathrm{H}_{2} \mathrm{SO}_{4}$ (actual), calculated from the

\section{TABLE V}

$\begin{array}{lccccccc}N & \Delta \overline{\mathrm{F}}_{298} & \overline{\mathrm{L}}_{290} & \Delta \overline{\mathrm{H}}_{290} & \overline{\mathrm{C}}_{P 298} & \overline{\Delta \Gamma} & \overline{\mathrm{H}}_{\circ} & \mathrm{I} \\ 0 & -\infty & -20600 & 0 & 10.21 & 0 & \ldots \ldots & \ldots \ldots \\ 0.0411 & -982 & -16370 & +4230 & 27.65 & 17.25 & -770 & 97.6 \\ 0.101 & +1995 & -12930 & +7670 & 14.71 & 4.31 & +6420 & 9.72 \\ 0.160 & +4330 & -10500 & +10100 & 22.45 & 12.05 & +6605 & 60.96 \\ 0.363 & \ldots \ldots & -4600 & +16000 & 38.63 & 28.22 & +7820 & \ldots \ldots\end{array}$

${ }^{20}$ Lewis and Randall, This Journat, 43, 237 (1921).

${ }^{21}$ Biron, J. Russ. Phys. Chem. Soc., 31, 190 (100). Data reproduced, Domke and Bein, Z. anorg. Chem., 43, 143 (1905).

22 Ref. 20 , p. 244.

${ }^{23}$ Lewis and Randall, This Journal, 43, 1128 (1921). 
equation $\Delta \mathrm{F}=3 \mathrm{R} T \ln \left(j m 4^{1 / 3}\right)$, are given for our concentrations (Col. 1) and for the temperature $T=298$ (Col. 2) in Table V.

The values of $\bar{L}_{290}=\overline{\mathbf{H}}-\mathrm{H}^{\circ}$ (Col. 3, Table $\mathrm{V}$ ) have been recalculated from data given by Brönsted, the value for infinitely dilute sulfuric acid $(N=\mathrm{O})$ being estimated by extrapolation. The values for $\overline{\mathrm{c}}_{p\left(\mathrm{H}_{2} \mathrm{SO} \mathrm{O}_{4}\right)}$ (Col. 4 , Table V) are calculated from the same data used for $\mathrm{C}_{p \mathrm{H}_{2} \mathrm{O}}$. By special treatment of the data for dilute solutions, $\bar{c}_{p}$ for infinitely dilute solutions was found to be 10.21 . The values of $\Delta \overline{\mathrm{H}}_{290}, \Delta \bar{\Gamma}, \overline{\mathrm{H}}_{0}$ and I are calculated in a manner entirely analogous to that used for water, and the results are given in Table $\mathrm{V}$, Cols. 6,7 and 8 , respectively. In order to calculate $\Delta \overline{\mathrm{F}}$ at the temperatures of our experiments, we have to make some assumption as to the change of $\Delta \bar{\Gamma}$ with the temperature. We have no data on this point. However, the fact that the fugacity of water, calculated in an analogous manner, assuming $\Delta \overline{\mathrm{T}}_{\mathrm{H}_{2} \mathrm{O}}$ constant, gave values so near the experiment justifies us in assuming $\Delta \bar{\Gamma}_{\mathrm{H}_{2} \mathrm{SO}}$ constant. On these assumptions, substituting in the appropriate values of the constants from Table V, we have calculated the activity of sulfuric acid at the temperature of our experiments. The values of $\alpha_{\mathrm{H}_{2} \mathrm{SO}_{4}}$ are given in Table III, Col. 6. These values, like those for the fugacity of water, must be corrected for the effect of the excess pressure, in this case the total pressure $P$. Corrected values are given in Table III, Col. 7. It will be noted that in one case the activity of sulfuric acid changes $0.12 \%$ per atmosphere added pressure.

Fugacity of Sulfur Dioxide. - It now remains to calculate the fugacity of the sulfur dioxide. If sulfur dioxide and water vapor were both perfect gases it would suffice to subtract from the measured equilibrium pressure the corrected pressure for water, plus the vapor pressure of sulfur (negligible in all experiments), the remainder being the partial pressure of sulfur dioxide. However, neither sulfur dioxide gas nor water vapor is a perfect gas at our temperatures and pressures. Thus in one case the vapor pressure of water is 98.0 atmospheres and its fugacity (the thermodynamically equivalent perfect gas pressure) is 83 atmospheres, while in the case of sulfur dioxide the assumption of the perfect gas laws would give 99 atmospheres, while the value we are about to calculate is 38 atmospheres. Other methods are therefore necessary. Unfortunately very little is known about the equation of state of mixed gases. However, Lewis and Randall have assumed, with considerably plausibility, ${ }^{24}$ that just as mixtures of liquids, where the molecules are far apart and where there are no polar forces, are likely to form perfect solutions, the activity of each constituent being proportional to its mol fraction, so gas mixtures in which the molecules are many times further removed, and where polar forces are still less, are still more likely to form perfect solutions. If this

24 Unpublished Treatise on Thermodynamics. 
is the case we may apply the equation for a perfect solution, ${ }^{25} i . e$,

$$
f=f_{0} N \text {, }
$$

where $f_{0}$ is the fugacity of the pure substance at the temperature and total pressure of the mixture, $N$ the mol fraction, and $f$ the desired fugacity of the desired constituent in the mixture. In applying this equation to our case, we may first consider the water. Here we have Equation 3 already used connecting fugacity and pressure. To find $f_{0}$ therefore we merely have to solve for $f$ in this equation at the total equilibrium pressure $P_{\mathrm{E}}$. of course actually pure water vapor could not remain a vapor at certain of the temperatures and total pressures used. Thus in Case 7 pure water has a vapor pressure of only 84.0 atmospheres; at pressures above this water would condense into a liquid, the fugacity remaining essentially constant. But just as in certain liquid mixtures in which the law of perfect solutions holds we are compelled to treat them as if they were mixtures, one of the components of which is a supercooled liquid, so here we may treat our water vapor as a supercooled gas, and, applying our equation, find the values of $f^{\circ} \mathrm{H}_{2} \mathrm{O}$ given in Table III, Col. 9 . It is perhaps worthy of note that in Case 7 the fugacity $f^{\circ} \mathrm{H}_{2} \mathrm{O}$ is only 93.4 atmospheres, while the total pressure is 185.0 atmospheres. Having found $f^{\circ} \mathrm{H}_{2} \mathrm{O}$ we may divide through by the values of $f^{\circ} \mathrm{H}_{2} \mathrm{O}$ corrected for pressure and obtain $N_{\mathrm{H}_{2} \mathrm{O}}$, the mol fraction of $\mathrm{H}_{2} \mathrm{O}$. The mol fraction of $\mathrm{SO}_{2}$, given in Col. 10 , Table III, is obviously $1-N_{\mathrm{H}_{2} \mathrm{O}}$. (The small vapor pressure of sulfur may be neglected.) Now knowing the mol fraction of sulfur dioxide we may find the actual fugacity of sulfur dioxide by reversing our procedure for water. Unfortunately, however, we have no experimental information about the equation of state for sulfur dioxide extending to our pressures and temperatures. ${ }^{26} \mathrm{We}$ may however assume that at corresponding states it is the same as that of carbon dioxide. For the temperature and pressure interval corresponding to those in which we are interested the equation of van der Waals, $i$. e., $\left(p-a / v^{2}\right)(v-b)=R T$, holds satisfactorily for carbon dioxide if we use the values of $a$ and $b$ calculated from critical data. We may therefore assume the same equation for sulfur dioxide, using as values of the constants $\mathrm{a}$ and $\mathrm{b}$ those calculated from the critical constants in the usual manner. We shall take as the critical pressure of sulfur dioxide 77.65 atmospheres, and as the critical temperature $430.24^{\circ} \mathrm{K}$. Using these values, $\mathrm{a}$ and $\mathrm{b}$ are found to be for one $\mathrm{mol}$ of gas, $6,775,000$ and 56.9 , respectively. It may be shown that for a gas which obeys van der Waals' equation the fugacity is given by the equation,

$$
\log f=\log \frac{\mathrm{R} T}{(\mathrm{v}-\mathrm{b})}+\frac{1}{2.3026}\left(\frac{\mathrm{b}}{\mathrm{v}-\mathrm{b}}-\frac{2 \mathrm{a}}{\mathrm{R} T \mathrm{v}}\right)
$$

${ }^{25}$ Lewis, Proc. Am. Acad., 43, 265 (1907).

${ }^{26}$ The data by Roth, Wied. Ann., 11, 1 (1880), extend only to $T=456.3$. 
For our temperatures and total pressures $P_{E}, \mathrm{v}$ may be found by solving van der Waals' equation. The values found are given in Table III, Col. 11. Substituting these values of $\mathrm{V}$ in Equation 9 gives $f^{\circ} \mathrm{SO}_{2}$. These values are given in Table III, Col. 12. These values multiplied by the mol fraction give the actual fugacity, $f_{\mathrm{SO}_{2}}$ (Table III, Col. 13) of the sulfur dioxide. Finally the equilibrium constant for the reaction $\mathrm{S}_{(\lambda \mu)}+$ $2 \mathrm{H}_{2} \mathrm{SO}_{4}(M)=3 \mathrm{SO}_{2}(\mathrm{~g})+\mathrm{H}_{2} \mathrm{O}(\mathrm{g})$ is given by the equation $\log K_{p}=3 \log$ $f_{\mathrm{SO}_{2}}+2 \log f_{\mathrm{H}_{2} \mathrm{O}}-2 \log a_{\mathrm{H}_{2} \mathrm{SO}_{4}}$, the values of $\log K_{p}$ so calculated being given in Table III, Col. 14.

Heat of Reaction.-In order to calculate the equilibrium constant at $25^{\circ}$ we must know the heat of the reacion as well as the specific heats of the constituents. Apparently the best values for the heat of formation of sulfur dioxide gas are those of Berthelot. ${ }^{27}$ Excluding the third series, the mean of his values is $69,390,{ }^{28}$ at $18^{\circ}$.

The direct values for the heat of solution of sulfur dioxide gas are not concordant. Thomsen ${ }^{29}$ measured the heat $\mathrm{SO}_{2}(1)=\mathrm{SO}_{2}(\mathrm{aq}) ; N=0.00320$; $N=0.00205$ and found $\Delta \mathrm{H}_{291}=1444 ; 1564$. Taking $\Delta \mathrm{H}_{291}=5370$ for the reaction $\mathrm{SO}_{2}(\mathrm{l})=\mathrm{SO}_{2}(\mathrm{~g}),{ }^{30}$ we find for the heat of the reaction $\mathrm{SO}_{2}(\mathrm{~g})=$ $\mathrm{SO}_{2}$ (aq); $N=00205 ; \Delta \mathrm{H}=6935 \mathrm{cal}$. 'This is in close agreement with the corresponding values for $\Delta \mathrm{H}$ calculated from data ${ }^{31}$ on the vapor pressure of sulfurous acid solutions at various temperatures and concentrations. We shall take $\Delta \mathrm{H}=6950$ for the concentration used by Thomsen in the experiments about to be mentioned. The heat of the reaction $\mathrm{Cl}_{2}(\mathrm{aq})+$ $\mathrm{SO}_{2}(\mathrm{aq})+2 \mathrm{H}_{2} \mathrm{O}=\mathrm{H}_{2} \mathrm{SO}_{4}(\mathrm{aq})+2 \mathrm{HCl}(\mathrm{aq})$ has been measured by Thomsen ${ }^{29}$ for $\mathrm{H}_{2} \mathrm{SO}_{4}$ of the mol fractions $0.000286,0.000507,0.000536$. The values for $\Delta \mathrm{H}$ given are $-74320,-73780,-73620$, respectively. Correcting to infinite dilution, these become $-75120,-75200,-75090$, respectively; average, -75140 . The best value for $\Delta \mathrm{H}_{291}$ for the reaction $\mathrm{Cl}_{2}(\mathrm{~g})+$ $\mathrm{H}_{2}(\mathrm{~g})=2 \mathrm{HCl}(\mathrm{aq}) ; N=0$ is $-78400 .{ }^{32}$ The best value for the heat of formation of $\mathrm{H}_{2} \mathrm{O}(1)$ at $18^{\circ}$ is $68330 .{ }^{17}$ The best value for the heat of vaporization of water at $18^{\circ}$ is $\Delta \mathrm{H}=+10.525 .{ }^{17} \Delta \mathrm{H}_{291}$ for the reaction $S_{\mathrm{r}}=\mathrm{S}_{\lambda}$ will be taken as +350.33

${ }_{27}$ Berthelot, Ann. chim., [5] 22, 428 (1881).

${ }^{2}$ For a discussion of this value see Ferguson, This Journal, 40, 1626 (1918).

29 Thomsen, "Thermochemische Untersuchungen," I,eipzig, 1882, vol. II, p. 250.

${ }^{30}$ Mathias, Compt. rend., 106, 1149 (1888).

${ }^{31}$ Linder, Monatsh., 33, 645 (1912). Calculated $\Delta \mathrm{H}$ for the concentrations of $0.000534 ; 0.00234 ; 0.01212 ; 0.03750 \mathrm{~g}$. SO2 per cc. are $9130 ; 7700 ; 6970 ; 6680$, respectively. The value directly measured by Thomsen, ${ }^{29}$ i. e., $\Delta \mathrm{H}=7700 \mathrm{cc}$. for $1 \mathrm{~mol}$. of $\mathrm{SO}_{2}$ to 250 mols. of $\mathrm{H}_{2} \mathrm{O}$, is apparently in error due to some analytical trouble. Berthelot's (Ann. chim., [VI] 1, $74(1884)$ ) value, $\Delta \mathrm{H}_{285}=8.34$ for $\mathrm{SO}_{2}(\mathrm{~g})=\mathrm{SO}_{2}$ (aq) $; 13.3 \mathrm{~g}$. per liter is somewhat less in error due to the same reason. Berthelot's values for heat of dilution of aqueous sulfurous acid ( $84 \mathrm{~g}$. per liter) with 5 volumes of water, namely $\Delta \mathrm{H}_{285} 280$, is, however, consistent with that calculated from Linder.

32 Ref. 17, p. 1977 
Therefore for the reaction $\mathrm{S}_{\lambda}+2 \mathrm{H}_{2} \mathrm{SO}_{4}(\mathrm{aq})=3 \mathrm{SO}_{2}(\mathrm{~g})+2 \mathrm{H}_{2} \mathrm{O}(\mathrm{g}) \quad \Delta \mathrm{H}_{291}=$ +95450 . The heat capacity of the various substances involved will be taken as $\mathrm{C}_{p}\left(\mathrm{~S}_{\lambda}\right)=5.4+0.05 \mathrm{~T} ;{ }^{33} \quad \mathrm{C}_{p}\left(\mathrm{H}_{2} \mathrm{SO}_{4}, M\right)=10.2 ;^{34} \quad \mathrm{C}_{p}\left(\mathrm{SO}_{2} \mathrm{~g}\right)=7.0+$ $0.0071 T-0.00000186 T^{2} ;{ }^{35} \quad \mathrm{C}_{p}\left(\mathrm{H}_{2} \mathrm{O} \mathrm{g}\right)=8.81-0.0019 T+0.00000222 T^{2}{ }^{36}$ From these data $\Delta \Gamma$ may be calculated as $\Delta \Gamma=12.80+0.0125 T-$ $0.00000114 T^{2} ; \Delta \mathrm{F}$ for any temperature is therefore given by the equation

$$
\Delta \mathrm{F}=+91205-12.8 T \ln T-0.00625 T^{2}+0.00000019 T^{3}+\mathrm{I} T .
$$

This is for the reaction $\mathrm{S}_{\lambda}+2 \mathrm{H}_{2} \mathrm{SO}_{4}(M)=3 \mathrm{SO}_{2}(\mathrm{~g})+2 \mathrm{H}_{2} \mathrm{O}(\mathrm{g})$. The reaction actually measured differs from this in that $S_{(\lambda \mu)}$ was used instead of $S_{\lambda}$. Lewis and Randal1 ${ }^{33}$ have given a table for $\Delta F$ for the reaction $S_{\lambda}=$ $S_{\lambda}$ at various temperatures which allows us to correct our measured values of $\Delta \mathrm{F}$ in order to use equation 10. Having $\Delta \mathrm{F}$ at our temperatures we may calculate I, the values determined being given in Table III, Col. 15. Using the mean of these values, we may calculate $\Delta F$ for $298^{\circ}$ for the reaction $\mathrm{S}_{\lambda}+2 \mathrm{H}_{2} \mathrm{SO}_{4}(M)=3 \mathrm{SO}_{2}(\mathrm{~g})+2 \mathrm{H}_{2} \mathrm{O}(1)$, the value found being +31500 .

It is difficult to say how much this value may be in error. The most serious source of error seems to be the uncertainty in the heat of formation of sulfuric acid and sulfur dioxide. These values may readily be in error by $\pm 2000 \mathrm{cal}$. The next most serious source is the arbitrary assumption that $\Delta \Gamma$ for sulfuric acid is constant over the temperature range employed. This assumption is probably not correct but it would be even more arbitrary to make any other in the absence of further data. The error introduced here may be as much as \pm 1000 cal. The experimental errors which are likely are the effect on the fugacity of the sulfuric acid and water of the solubility of sulfur dioxide, which we have neglected, and an effect on the concentration of the sulfuric acid due to the same cause. Errors due to uncertainty of temperature and pressure readings and due to thermodytramic data and methods employed other than those mentioned above, are almost certainly not over $500 \mathrm{cal}$. The two measurements made with acic of the mol fraction 0.041 aie subject to another source of error, namely, the side reaction $2 \mathrm{H}_{2} \mathrm{O}(\mathrm{g})+3 \mathrm{~S}_{(\lambda \mu)}=\mathrm{SO}_{2}(\mathrm{~g})+2 \mathrm{H}_{2} \mathrm{~S}(\mathrm{~g})$. The amount of correction due to this source can be calculated, and the bracket values in Table III have been corrected by this amount, assuming best values for $\Delta \mathrm{F}$ for sulfur dioxide and hydrogen sulfide. This correction should be negligible at the higher concentrations. Excepting this correction, the probable sources of error are such that the above value for $\Delta \mathrm{F}$ is too low if anything.

\section{Summary.}

The reactions of liquid sulfur with aqueous sulfuric acid have been studied

${ }^{33}$ Lewis and Randall, This Journal, 33, 476 (1911).

${ }^{34}$ Table V.

${ }^{35}$ Lewis and Randall, This Journal, 36, 1133 (1912).

${ }^{33}$ Ref. 35, p. 1132. 
over a wide range of conditions. At low concentrations of sulfuric acid two reactions take place simultaneously, namely, (1) $\mathrm{S}_{(\lambda \mu)} \cdot 2 \mathrm{H}_{2} \mathrm{SO}_{4}(\mathrm{aq})=$ $2 \mathrm{H}_{2} \mathrm{O}(\mathrm{l})+3 \mathrm{SO}_{2}(\mathrm{~g})$ and (2) $4 \mathrm{~S}_{\left(\lambda_{\mu}\right)}+4 \mathrm{H}_{2} \mathrm{O}(\mathrm{l})=3 \mathrm{H}_{2} \mathrm{~S}(\mathrm{~g})+\mathrm{H}_{2} \mathrm{SO}_{4}(\mathrm{aq})$. These reactions are both reversible. In the acids of higher mol fraction than 0.05 , and at temperatures up to the critical point of water, Reaction 2 becomes negligible. Equilibrium pressures for Reaction 1 have been measured for acids of mol fraction ranging from 0.041 to 0.363 , and at temperatures ranging from $527^{\circ} \mathrm{A}$ to $613^{\circ} \mathrm{A}$, using a new type of apparatus. The vapor pressures of various concentrations of sulfuric acid have been measured with the same apparatus. Using these and other existent data, the free energy for the reaction $\mathrm{S}_{(\lambda)}+2 \mathrm{H}_{2} \mathrm{SO}_{4}(M)=2 \mathrm{H}_{2} \mathrm{O}(\mathrm{g})+3 \mathrm{SO}_{2}(\mathrm{~g})$ has been calculated to be +31500 cal. at $25^{\circ}$ and standard conditions. From these and other data the free energy of both aqueous sulfuric acid and sulfur dioxide may be calculated.

A new type of apparatus for measuring equilibrium or vapor pressures of corrosive liquids up to high pressures and temperatures has been described.

Bergeley, CaLifornia.

\section{QUANTITATIVE ANALYSIS BY CENTRIFUGE.}

By Olof Arrhenius.

Received November 4, 1921 .

Chemical investigators in the domains of biology, medicine and soil analysis have ever sought for rapid methods of experiment and analysis. In these sciences experimental deviations are so great that one must greatly increase the number of samples for analysis in order to get reliable results. $^{1}$ Speed rather than great precision is needed in such cases; one needs methods less precise than those which he would employ where the conditions more constant. Accordingly we have in text-books many rapid methods; for example, the colorimetric, the nephelometric, etc.

Curiously enough very little use is made, in such rough quantitative researches, of direct readings of the volume of the precipitate, although this is a very common method in the so-called mechanical analysis of soils. This method attains its greatest accuracy when the columns of precipitate are compressed by means of centrifugal force. In the dairy and in clinical technique the centrifuge has been much used, but it is rarely used for quantitative work in the inorganic laboratory. Nevertheless, the centrifugal method can be used with considerable accuracy. For example Hedin ${ }^{2}$ succeeded in determining very satisfactorily the

${ }^{1}$ For example Waynicke points out that from an area as small as half an acre, one must collect over 80 samples for analysis, in order to get a moderately accurate result. (Univ. Cal. Publ. Agr. Sci., 3, 1918.)

${ }^{2}$ Hedin, Skand. Arch. f. Physiol., 5, (1895). 